\title{
Do experimental ao ancestral - Entrevista com Mesias Maiguashca (Quito, 1938-)
}

\author{
Jonathan Andrade, Rogério Costa \\ Universidade de São Paulo (Programa ECA) \\ jonyfree2015@gmail.com \\ jaens.bandcamp.com
}

As experiências artístico-acadêmicas de Mesias Maiguashca fazem dele um compositor e pesquisador significativo para o contexto musical contemporâneo. Desde os seus primeiros passos com a música eletrônica em 1967 nos estudos WDR em Colônia, Alemanha em parceria com Stockhausen, até sua obra conceitual-experimental La canción de la tierra, estreada na madrugada do Inti Raymi ${ }^{1}$ no dia 21 de Junho de 2013, é possível perceber um rico percurso que abarca um mundo de possibilidades estéticas, recursos tecnológicos e principalmente transmutações como músico experimentador e fomentador de processos criativos sócio musicais ${ }^{2}$ em seu país natal, o Equador.

Neste longo percurso, dentre outras atividades, Maiguashca fez parte de um grupo coordenado por K. Stockhausen que, na década de 1970 realizou diversas apresentações da obra Stimmung, testemunhou a efervescência artística do período entre 1965 e 1975, onde os movimentos Fluxus e a Neue Musik (música nova) foram os paradigmas criativos e composicionais, participou no desenvolvimento de tecnologias analógicas e digitais no IRCAM (Paris, França) e posteriormente, entre 1978 e 1987, foi professor de Música Eletroacústica no Centre Europée pour la Recherche Musicale de Metz (CERM), na França. Graças a

\footnotetext{
10 Inti Raymi é uma festa tradicional indígena comemorada em toda a zona andina, nos dias 21 e 22 de Junho (quando o sol está mais próximo da terra). A celebração tem como propósito adorar o deus Inti (Sol); dentro da cosmologia indígena, o deus Inti é o fornecedor de calor, comida e vitalidade aos homens e mulheres, formando uma parte fundamental da existência do índio andino. 2 O compositor Mesias Maiguashca vem alternando suas atividades entre a Europa e o Equador. No Equador, tem ministrado oficinas sobre música experimental e fomentado ativamente a criação e a manutenção de espaços dedicados à criação no contexto musical e equatoriano. Além disso, o compositor tem atuação destacada na defesa direitos indígenas.
} 
estas experiências Maiguashca integra um restrito círculo acadêmico internacional e desempenha um papel importante enquanto experimentador, criador e pedagogo, tendo ministrado diversas palestras, conferências e apresentado suas obras em vários países da Europa e da América.

Mas o que complementa a singularidade de Maiguashca é o vínculo que ele mantém com suas raízes. Seu trabalho representa uma projeção do músico experimental através da realidade local da América do Sul. O resultado dessa aproximação com as manifestações culturais nativas andinas pode ser percebido desde sua obra eletroacústica ayayayayay (1971), continuando com a composição El Oro (1992), para flauta, violoncelo e fita magnética, seu ciclo composicional denominado Reading Castañeda4 (1983-1993), Boletin y Eligíade las Mitas (2006), Canción de la Tierra (2011-2012), e a instalação sonora Yakushimi (2012-2013). Nestas obras Maiguashca desenvolve suas ideias performáticas sobre as sonoridades nativo ancestrais, fomentando a construção de objetos sonoros ${ }^{5}$, trabalhando com performance corporal e desenvolvendo processos criativos que dialogam com conceitos da cosmovisão andina e o indigenismo 6 .

Maiguashca representa uma visão singular sobre o significado do paradigma da música experimental. Atravessando uma geração repleta de inovações criativas, estéticas e técnicas, chega ao século XXI equipado com todos esses recursos para criar um nexo com o popular e com o nativo ancestral. Por outro lado, se afasta do folclorismo estabelecido, contextualizando diversos elementos da realidade indígena de forma inovadora e transparente mediante processos conceituais de hibridismo e transculturalidade que sintetizam um processo criativo sonoro-musical que envolve o ancestral e o experimental. Por isso é

\footnotetext{
3 Ayayayayay é uma peça eletroacústica de Maiguashca realizada com gravações da paisagem sonora-musical equatoriana: sons ambientes, sons urbanos típicos, diálogos e conversas, festas tradicionais e evidentemente, música.

${ }^{4}$ Este ciclo foi inspirado em leituras dos livros de Carlos Castañeda sobre a prática de bruxaria dos índios Yaquis de México e pelas primeiras experiências com o mundo sonoro dos "objetos sonoros" de metal que Maiguashca estava desenvolvendo.

5 Diferentemente do conceito "Objeto Sonoro" descrito por P. Schaeffer, Mesias Maiguashca trabalha na criação de diferentes artefatos sonoros (esculturas sonoras), construídos com peças de metal penduradas num cubo metálico amplificado por microfones de contato, passando posteriormente a utilizar a madeira, com formas representativas com temáticas indígenas.

${ }^{6}$ Conferir também as ideias expostas em BECKER, Marc. Comunistas, indigenistas e indígenas en la formación de la Federación Ecuatoriana de Indios y el Instituto Indigenista Ecuatoriano. Iconos, Revista de Ciências Sociales, Quito, n. 27, p. 135 a 144, 2007.
} 
importante conhecer suas ideias quando debatemos sobre a complexidade da música contemporânea e a crise da modernidade.

\section{Entrevista}

Entrevistador (E): A partir da sua experiência, como você observa o contexto da música experimental atual na Europa, e a partir desta perspectiva, quais são os reflexos desta na experimentação musical da América do Sul?

Maiguashca (M): Na década de 1980 a vanguarda da nova música europeia explodiu em inúmeros direcionamentos. A frente conceitual, estética e técnica do que seria o futuro da música se fragmentou. Várias são as razões. Certamente, uma das mais importantes é o aparecimento de novas estratégias ligadas à digitalização, aos diferentes meios eletrônicos e à massificação das vias de informação através da internet. Além disso, há a irrupção de outras formas de pensamento, de expressão, de conteúdos e tradições até então desconhecidas pelo mainstream na Europa. Acredito que nesta intersecção se cria uma via importante de desenvolvimento idiossincrático da música experimental latinoamericana.

E: Você teve oportunidade de experimentar e aprendeu a trabalhar com diversas ferramentas analógicas desenvolvidas na Europa, testemunhando o processo de digitalização pelas quais passaram aquelas ferramentas desde a década de 1990 . De que forma esse processo ajudou ou limitou o músico compositor experimental atual?

M: As ferramentas analógicas desenvolvidas desde os anos 1950 na Europa abriram brechas, canais e direcionamentos. No princípio essas ferramentas foram utilizadas dentro de estúdios e instituições de difícil acesso. A digitalização dessas técnicas e sua generalização através da internet, além da educação massiva, tem democratizado enormemente seus usos e aplicações: materiais e know-how agora são de fácil acesso. Seguramente essa democratização criará um novo momento no desenvolvimento da criação artística e musical porque acredito que as novas tecnologias criam novos significados, e novos significados, complementarmente, criam novas técnicas. 
E: Quais são suas considerações sobre os grupos Fluxus e Neue Musik, e de que forma seus processos conseguiram atravessar as décadas chegando na composição atual?

M: O Fluxus ${ }^{7}$ foi um espaço de exploração sem medos ou temores, mas também sem muita disciplina. Sua perspectiva foi fazer o questionamento das formas estéticas e técnicas estabelecidas criando um vácuo para poder começar, por assim dizer, a partir de zero. Desse vácuo nasceram inúmeras ideias, direcionamentos, dúvidas e conceitos. Nas suas ações já estavam implícitos os desenvolvimentos que estarão projetados até o final do século. O Neue Musik era mais disciplinado e pragmático, voltado à criação de "obras" e recorrendo a um enorme acabamento técnico, especialmente no que diz respeito à forma.

E: Na sua opinião qual é a situação da música contemporânea com relação à variedade de técnicas e possibilidades tecnológicas existentes e disponíveis hoje?

M: Acredito que a criação musical contemporânea enfrenta uma pluralidade sem precedentes na história. Mas justamente essa multiplicidade vai forçar o criador a todo um percurso de decisões preliminares de ação artística. A responsabilidade frente a esta multiplicidade de meios é igualmente sem precedentes. O criador tem que se construir humana e tecnicamente antes de poder agir artisticamente.

E: De que forma a educação musical se transformou com o desenvolvimento dos vários procedimentos na criação musical dos últimos 60 anos?

M: A necessidade de renovar a educação musical já era evidente em meados do século XX na Europa causada principalmente pela pressão criada pela Neue Musik $^{8}$. A necessidade de integrar novos conceitos ligados a ela (atonalidade,

\footnotetext{
${ }^{7}$ Fluxus foi um movimento artístico de cunho libertário, caracterizado pela mescla de diferentes artes, primordialmente das artes visuais mas também da música e da literatura Teve seu momento mais ativo entre a década de 1960 e 1970, se declarando contra o objeto artístico tradicional como mercadoria. Menos que um estilo, um conjunto de procedimentos, um grupo específico ou uma coleção de objetos, o movimento fluxus traduz uma atitude diante do mundo, do fazer artístico e da cultura que se manifesta nas mais diversas formas de arte: música, dança, teatro, artes visuais, poesia, vídeo, fotografia e outras. Seu nascimento oficial está ligado ao Festival Internacional de Música Nova, em Wiesbaden, Alemanha, em 1962, e a George Maciunas (1931-1978), artista lituano radicado nos Estados Unidos, que batiza o movimento com uma palavra de origem latina, fluxu, que significa fluxo, movimento, escoamento (http://enciclopedia.itaucultural.org.br/termo3652/fluxus acessado no dia 24 de abril de 2015).

8 O termo Neue Musik (Música Nova) sempre foi utilizado de forma vaga e imprecisa na história da música. Aqui Mesias Maiguashca parece se referir especificamente à música europeia mais experimental e "avançada" da primeira metade do séc. XX representada por compositores tais
} 
serialismo, música concreta, electronic music, técnicas multimídias etc.) criaram na Europa a necessidade de um novo tipo de formação musical. Hoje quase não há escolas sem departamentos da música nova e/ou estúdios de música eletroacústica. A prática, cada vez mais intensa da música nova forçou a escola a oferecer uma formação acadêmica específica, criando uma geração de artistas incomparável em qualidade e quantidade, que criou o fermento necessário à criação musical e enraizamento progressivo na sociedade.

$\mathrm{Na}$ América Latina, o processo tem sido mais lento. O conservatório ainda continua "conservando" as tradições da música europeia do início do século XX. Mas, certamente, alguns deles, principalmente as universidades, começam a promover uma educação mais atualizada e mais próxima das práticas musicais contemporâneas, começando com fazer da escola de música uma fonte de criação e de irradiação.

E: Na oficina que você ministrou Existe uma sintaxe Musical? ${ }^{9}$, quais foram suas impressões quando você apresentou diferentes métodos de estruturação musical, usando o ruído e improvisação livre como estratégias para a construção de discurso sonoro-musical?

M: Na educação formal tradicional o aluno se aproxima do discurso musical através de uma série de disciplinas tradicionais (notação, contraponto, harmonia etc.), que poderiam ser agrupadas sob o conceito de Tonsatz (em alemão, "escrita"). Mas todas essas disciplinas se relacionam com um estilo histórico preciso, o classicismo europeu. Na oficina oferecida, eu tentei formalizar estruturas musicais funcionais que não se referem ao classicismo, mas sim, a uma prática contemporânea, que inclui sons harmônicos, não harmônicos e ruídos. Foi um ponto importante liberar essas experiências da tirania da notação tradicional e me referir a outros tipos de notação, por exemplo, conceitual, verbal e gráfica. Foi importante para mim trabalhar com unidades sonoras

como Karlheinz Stockhausen, Pierre Boulez, Luciano Berio, Henri Pousseur, Luigi Nono, György Ligeti etc. e seus desdobramentos atuais que abarcam tendências muito diversificadas.

9 Organizado pelo Centro de Arte Contemporáneo de Quito, Equador, nos dias 8 e 9 de Julho de 2013 a oficina Existe uma sintaxe musical? fez parte da mostra Los Sonidos Posibles quando foi apresentado o trabalho musical e acadêmico de Maiguashca. Segundo Maiguashca: Na linguagem, a sintaxe estuda as maneiras em que as palavras são combinadas para formar estruturas maiores de comunicação. Este conceito se aplica à música? Certamente não, se interpretarmos o conceito literalmente. Mas a sintaxe oferece vários elementos formais para estruturar o que poderíamos chamar de um "discurso musical". Músicos de diferentes formações participaram da oficina que terminou com uma grande sessão de improvisação. 
concretas (não necessariamente escritas) e tentar dinamiza-las através de conceitos semelhantes à sintaxe da prática linguística. Para mim foi um grande prazer perceber que, partindo deste método, conseguimos, em um curto espaço de tempo, criar experiências musicais individuais e coletivas muito diferenciadas e que foram apresentadas num concerto-performance.

E: Como a música experimental pode reconstituir o conceito ritualístico que possuem as experiências musicais e como esse conceito dialoga com as formas musicais nativas indígenas?

M: Uma das características da prática da Neue Musik era seu caráter exclusivamente eurocêntrico. Tudo o que era periférico era percebido com desconfiança, por exemplo, o relacionamento com outras culturas e outras formas de perceber a música. Neste contexto, foi criada a expressão außereuropäische Musik, (em alemão, música fora da Europa). Mas esse "fora da música de Europa" tem acumulado suas próprias energias e formado uma tradição forte e idiossincrática, diferente da música europeia. Neste contexto, é possível perceber na atualidade, um direcionamento para a música tradicional e indígena na América Latina e em outros lugares do mundo. Além disso, o aspecto experimental da Neue Musik criou campos de ação e de coabitação com outras formas de fazer música, por exemplo, com a música popular, tradicional e/ou indígena. Dessa forma, estamos desenvolvendo um campo de ação amplo e promissor que poderia muito bem criar uma música "erudita" latino-americana original e forte.

E: Qual foi o procedimento utilizado na fusão dos elementos da música experimental com a cosmovisão andina em sua obra Canción de la Tierra?

M: Meus mais recentes trabalhos Boletín y Elegía de las Mitas, Canción de la Terra e a instalação Yakushimi representam um esforço intenso e consciente para superar aquele paradoxo que vem determinando minha vida e meu trabalho artístico: estar enraizado em duas tradições (andina e europeia), estar "montando em dois cavalos". Nestes trabalhos, eu comecei a sintetizar o que eu herdei e que eu aprendi, já que as duas tradições são partes constitutivas do meu ser humano e artístico. Durante o meu desenvolvimento tenho conseguido formar algo que eu poderia denominar como a "minha linguagem musical", que é constituída de uma série de procedimentos conscientes ou inconscientes com os quais normalmente me identifico. Uma vez constituída uma linguagem, o 
próximo passo seria descobrir "o que dizer" com ela. O novo paradoxo é que a "linguagem" está intimamente ligada ao "que dizer". Eu me encontro especificamente aí: fazendo um esforço para unificar "o que dizer" com o "como dizer". Os resultados têm sido as obras mencionadas. Eu me reconheço nelas, especialmente em suas contradições. Mas elas também são parte do meu percurso.

E: De que forma você considera que o material musical e cultural andino alimenta o paradigma da música contemporânea?

M: Acredito que todo artista leva em sua "mochila" experiências vitais que determinam seu trabalho. Na medida em que ele possa criar um trabalho expressivo e forte, ele estará contribuindo para a construção de paradigmas coletivos. Do mesmo modo, o artista andino: se ele pode, a partir de suas experiências vitais, criar um repertório artístico expressivo, ele estará necessariamente contribuindo para a consolidação dos paradigmas da música contemporânea e parcialmente participando de sua determinação.

E: Você colaborou e trabalhou com o compositor boliviano Cergio Prudencio e a Orquesta Experimental de Instrumentos Nativos (OEIN), em La Paz, para a composição e performance de Chulyadas - Tarkyadas - Sikuryadas (2011). Quais foram os procedimentos instrumentais, fenomenológicos e acústicos usados para criar esta obra?

M: Foi uma experiência bela e enriquecedora. Minha visita a La Paz em setembro de 2010, com a finalidade de me aproximar do trabalho da OEIN, foi novamente, uma confirmação da minha "esquizofrenia" cultural. Os primeiros ensaios foram muito emotivos e curiosos: eu tinha a impressão de que já tinha ouvido há milhares de anos a música que estava escutando naquele momento. Mas depois de me ver confrontado a compor uma obra para o grupo, senti a necessidade de recorrer ao já "aprendido". Como uma nova surpresa, várias das características acústicas do grupo me remeteram às questões com as quais eu tive contato principalmente na música eletrônica: o intenso desejo de abandonar o sistema temperado de doze tons, o fascínio por eventos acústicos tais como batimentos de enorme complexidade e sons diferenciais etc. Foi um "horror-paraíso" escutar, numa pequena sala de ensaio, uma dúzia de instrumentos agudos tocando quase uníssono em fortíssimo! Que dor de dente e que epifania da alma! Mas acima de tudo, foi um prazer redescobrir o conceito de mistura para lidar com as 
diferentes tropas ${ }^{10}$, ou descobrir como gravar e interagir com um órgão desafinado (uma verdadeira orgia de parciais!). Finalmente recorri a métodos de composição já conhecidos. Mais uma vez, o conflito entre "o que dizer" e o "como dizer".

Links das peças de Mesias Mayguashca:

\section{AYAYAYAYAY}

http://www. maiguashca.de/index.php/es/1970-1979-a/316-051971ayayayayay-es

EL ORO 1992

http://www.maiguashca.de/index.php/es/1990-1999-a/376-311992-el-oro-es BOLETIN Y ELEGIA DE LAS MITAS

http://www. maiguashca.de/index.php/en/2000-2009-a/480-552006-boletin-yelegia-de-las-mitas-en

YAKUSHIMI

http://www. maiguashca.de/index.php/en/2012-a

\section{CANCIÓN DE LA TIERRA}

http://www. maiguashca.de/index.php/en/2011-a/371-702011-12-qla-cancionde-la-tierraq-en

10 O temo Tropas refere-se ao conjunto de instrumentos de sopro de diferentes qualidades e tessituras dentro de um grupo de música tradicional do altiplano. Existem diversas Tarkas (tipo de flauta andina) que agrupam-se formando as chamadas tropas tarkyanas. 